\title{
Radiofrequency ablation for treatment of frequent premature ventricular contractions by transradial access in a patient with severe vascular disease
}

\author{
Zuli $\mathrm{Fu}^{1}$, Qian $\mathrm{Xu}^{1}$, and Ruizheng $\mathrm{Shi}^{1}$ \\ ${ }^{1}$ Xiangya Hospital Central South University
}

September 28, 2020

\begin{abstract}
In radiofrequency catheter ablation of idiopathic ventricular arrhythmias, catheters are routinely sent into the heart through femoral arteries or femoral veins. But once femoral vessels are not suitable for puncture and approach, transradial artery access becomes the choice. Here, we report the case of a 73-year-old man with frequent premature ventricular contractions and severe vascular disease who successfully received radiofrequency catheter ablation through radial artery access.
\end{abstract}

\section{Keywords}

Radiofrequency catheter ablation; Premature ventricular contractions; Transradial artery access

\section{Introduction}

Radiofrequency catheter ablation (RFCA) has become the first-line treatment for idiopathic ventricular arrhythmias including premature ventricular contractions (PVCs) and ventricular tachycardia (VT), especially in patients with symptoms that couldn't be relieved by antiarrhythmic drugs. Catheters are generally sent into the heart via femoral arteries or femoral veins. Here, we present a case of successful ablation of frequent PVCs in aorto-mitral continuity by transradial artery access in a patient with severe vascular disease and multisystem disease.

\section{Case report}

A 73-year-old man, who had suffered from palpitations and fatigue for 2 years, was admitted to our clinic and diagnosed with symptomatic PVCs. After oral amiodarone of $600 \mathrm{mg} /$ day for 2 months without symptoms alleviation, he returned to our clinic for treatment of PVCs. He had a history of hypertension, chronic obstructive pulmonary disease, lacunar infarction, osteoporosis, and lumbar disc herniation. His heart auscultation revealed frequent premature beats. Surface 12-lead electrocardiography (ECG) showed similar left bundle branch block morphology and inferior axis with R/S transition between V2 and V3 in both monomorphic PVCs and VT (Figure 1). A 24-hour Holter electrocardiogram recorded 38223 PVCs/day with 489 bigeminies and 35\% VT of total beats. Echocardiography showed normal left ventricular ejection fraction $(\mathrm{LVEF}=61 \%)$, thickening interventricular septum, and ventricular diastolic dysfunction.

Since his surface 12-lead ECG indicated that the PVCs probably originated from the septal portion of the right ventricular outflow tract (RVOT) or aortic sinus ${ }^{1}$, electrophysiologic study at RVOT via right femoral vein was considered first. Three-dimensional electromagnetic mapping (CARTO 3, Biosense Webster, Diamond Bar, CA) and ablation catheter (Boston Scientific, Natick, MA) were performed via an 8-French multipolar electrode catheter with a 4-mm distal electrode. But no ideal ablation site in RVOT was mapped. Then we switched to electromagnetic map aortic sinus by femoral artery access. However, the physical 
examination revealed the absence of the right femoral artery pulse, and a right femoral artery puncture also failed. We next performed the left femoral artery approach but the catheter was obstructed at the level of the renal artery. Iliac femoral arteriography via the sheath indicated severe filling defects of the abdominal aorta. Thus, the first operation ended and the patient was sent back to the ward for further examination.

Afterward, CT angiography of the whole aorta was performed that showed severe aortic conditions: aortic arteriosclerosis, bilateral common, internal and external iliac arteries arteriosclerosis, multiple penetrating ulcers and aneurysm in the aortic arch, infrarenal abdominal aortic thrombosis and occlusion (Figure 2). The ultrasonic Doppler examination of upper limb arteries was unremarkable.

Since aortic aneurysm and peripheral arterial disease increase the risk of cardiovascular events, especially in patients combined with multisystem disease, endovascular repair should be considered ${ }^{2}$. Before the repair, frequent PVCs need to be treated. In the second procedure, general anesthesia and radial artery access were considered due to his special conditions. The coronary artery angiography was performed and showed $50 \%$ stenosis at the mid-portion in the left anterior descending artery, $80 \%$ stenosis at the distal left circumflex artery, and $40 \%$ stenosis in the proximal right coronary artery. The angiography of the aortic sinus showed aortic arch ectasia with the left common carotid artery and left subclavian artery involved.

Therefore, a 7F sheath was inserted with a large-tip 7F catheter for mapping and ablation through radial artery access. No ideal target in the thoracic aortic sinus was mapped at first, then we searched for areas below the aortic sinus. The earliest ventricular activation preceding the onset of the local QRS by 30 ms was recorded during sinus rhythm, with the catheter positioning at aorto-mitral continuity (AMC). Pace mapping was performed in this area and showed a $99 \%$ match. No earlier foci were found in the surrounding area. Radio-frequency energy delivery (180s, 35W) at the site eliminated the PVCs (Figure 3). Isoproterenol could not induce PVCs, and no PVC was observed during the 30 minutes waiting period. The overall procedure lasted 75 minutes. During a 3-day post-ablation follow-up, the patient did not feel obvious palpitations and no PVCs recurred. Two months later, he underwent endovascular stent-graft placement for the thoracic aortic aneurysm, until then no PVCs were found.

\section{Discussion}

Radiofrequency ablation has an important role in the therapy of ventricular arrhythmia ${ }^{3}$. In this case, we use a 7 French catheter through radial artery access to successfully ablate the PVC foci in a patient with severe peripheral artery disease and other concomitant diseases.

Radiofrequency ablation of left ventricular arrhythmia is usually manipulated through the femoral artery or atrial septal puncture. In the situation of thrombosis or occlusion of the femoral and iliac artery, the transfemoral artery route becomes impossible. The recumbent position is needed to avoid puncture disrupting, which may be poorly tolerated by patients with left ventricular dysfunction, lung disease, or back and hip pain. Despite bed rest, puncture-related complications such as hematomas, pseudoaneurysms, arteriovenous fistula, or need for blood transfusion or surgical arterial repair, can occur with the transfemoral approach ${ }^{4}$. Besides, as the population ages, patients with arrhythmias comorbid with peripheral artery diseases, aortic atherosclerosis, or tortuous aortas, will also increase, and the chance of encountering inaccessible femoral arteries will grow. These factors together affect patients' morbidity, satisfaction, length of hospital stay, health care costs, and drive the development of alternative vascular access for RFCA ${ }^{4}$. Therefore, to avoid limitations and complications related to the femoral artery access, the radial artery is proposed to be effectively used in RFCA. Evidence from observational studies and large randomized trials demonstrated that transradial access is associated with reduced risk for access-site bleeding and reduced mortality in high-risk patient subgroups ${ }^{5,6}$. A recent American Heart Association statement and the European Society of Cardiology recommends transradial access over transfemoral access as a Class IA indication for patients with acute coronary syndrome undergoing invasive management if performed by experienced radial operators ${ }^{7,8}$.

Radial artery spasm is the most frequent complication of TRA in an elective and emergent coronary intervention that can result in severe pain and possible failure of the procedure. But the risk of spasms can be avoided by rapid mapping of the optional sites with the minimal rotation of the catheter. He et $\mathrm{al}^{4} \mathrm{reported}$ 
the use of $5 \mathrm{~F}$ catheters for idiopathic left ventricular tachycardia ablation. They proposed that $5 \mathrm{~F}$ catheters could increase mapping accuracy and decrease the number of current applications, reduce radiofrequency power lost to the blood pool. 90 -cm long $6 \mathrm{~F}$ introducer sheaths, $5 \mathrm{~F}$ large-tip catheters, hydrophilic sheaths, and vasodilators were used to prevent patients from discomfort and radial artery spasm. Above all, the results may be attributed to the vast experience of the operator than the transradial approach. In this case, although the $7 \mathrm{~F}$ sheath and catheter were used for ablation, we used heparin to reduce radial artery spasm and no radial artery spasm was observed in the perioperative period.

Radial artery occlusion is another post-procedural complication of TRA. Risk factors associated with radial artery occlusion include age, female sex, low body mass index, diabetes, and previous radial artery access $^{9}$. There are several strategies to reduce the occurrence of radial artery occlusion ${ }^{9}:$ minimizing radial artery injury by a reduction in sheath and catheter size, adequate procedural anticoagulation, nonocclusive hemostasis, minimal pressure strategy together with short hemostasis time ([?]120 min), pre-puncture subcutaneous nitrates, and post-procedural pre-hemostasis intra-arterial nitrates, and systematic assessment of radial artery patency before discharge. In this case, owing to femoral arteries occlusion, access via the femoral artery carries the potential risk of cholesterol embolism, stroke, and even aneurysm rupture. RFCA via radial artery access comes to be the best option for treating the PVCs. We were not limited by the ability to manipulate the ablation catheter via the radial artery. We used a $7 \mathrm{~F}$ sheath and $7 \mathrm{~F}$ large tip catheter to ablate the PVCs origin foci by gentle rotation and advance of the catheter in 45 minutes and allowed a rapid mobilization of the patient. Typically, this technique lowers mortality and allows patients to go home sooner and recover faster.

\section{Conclusion}

This case raises the feasibility of using transradial access for radiofrequency catheter ablation in patients with frequent PVCs comorbid with severe peripheral artery diseases. No complications occurred during the perioperative period. Heart rhythm parameters were stable during a two-month follow-up. The long-term outcome needs further observation.

\section{References}

1. Adams JC, Srivathsan K, Shen WK. Advances in management of premature ventricular contractions. $J$ Interv Card Electrophysiol.2012;35(2):137-149.

2. Caro J, Migliaccio-Walle K, Ishak KJ, Proskorovsky I. The morbidity and mortality following a diagnosis of peripheral arterial disease: Long-term follow-up of a large database. BMC cardiovascular disorders. $2005 ; 5(1): 14$.

3. Al-Khatib SM, Stevenson WG, Ackerman MJ, Bryant WJ, Callans DJ, Curtis AB, Deal BJ, Dickfeld T, Field ME, Fonarow GC, Gillis AM, Granger CB, Hammill SC, Hlatky MA, Joglar JA, Kay GN, Matlock DD, Myerburg RJ, Page RL. 2017 AHA/ACC/HRS Guideline for Management of Patients With Ventricular Arrhythmias and the Prevention of Sudden Cardiac Death: Executive Summary: A Report of the American College of Cardiology/American Heart Association Task Force on Clinical Practice Guidelines and the Heart Rhythm Society. Circulation.2018;138(13):e210-e271.

4. He B, Jiang H, Lu Z, Zhang M, Hu X, Yang B, Huang H, Wu G, Wan J, Liu H, Wang X, Huang C. Feasibility and safety of transradial approach for catheter ablation of idiopathic left ventricular tachycardia. Clinical research in cardiology : official journal of the German Cardiac Society. 2011;100(1):37-43.

5. Valgimigli M, Frigoli E, Leonardi S, Vranckx P, Rothenbühler M, Tebaldi M, Varbella F, Calabrò P, Garducci S, Rubartelli P, Briguori C, Andó G, Ferrario M, Limbruno U, Garbo R, Sganzerla P, Russo F, Nazzaro M, Lupi A, Cortese B, Ausiello A, Ierna S, Esposito G, Ferrante G, Santarelli A, Sardella G, de Cesare N, Tosi P, van 't Hof A, Omerovic E, Brugaletta S, Windecker S, Heg D, Jüni P. Radial versus femoral access and bivalirudin versus unfractionated heparin in invasively managed patients with acute coronary syndrome (MATRIX): final 1-year results of a multicentre, randomised controlled trial. Lancet (London, England). 2018;392(10150):835-848. 
6. Ferrante G, Rao SV, Jüni P, Da Costa BR, Reimers B, Condorelli G, Anzuini A, Jolly SS, Bertrand OF, Krucoff MW, Windecker S, Valgimigli M. Radial Versus Femoral Access for Coronary Interventions Across the Entire Spectrum of Patients With Coronary Artery Disease: A Meta-Analysis of Randomized Trials. JACC Cardiovascular interventions. 2016;9(14):1419-1434.

7. Mason PJ, Shah B, Tamis-Holland JE, Bittl JA, Cohen MG, Safirstein J, Drachman DE, Valle JA, Rhodes D, Gilchrist IC. An Update on Radial Artery Access and Best Practices for Transradial Coronary Angiography and Intervention in Acute Coronary Syndrome: A Scientific Statement From the American Heart Association. Circulation Cardiovascular interventions. 2018;11(9):e000035.

8. Ibanez B, James S, Agewall S, Antunes MJ, Bucciarelli-Ducci C, Bueno H, Caforio ALP, Crea F, Goudevenos JA, Halvorsen S, Hindricks G, Kastrati A, Lenzen MJ, Prescott E, Roffi M, Valgimigli M, Varenhorst C, Vranckx P, Widimský P. 2017 ESC Guidelines for the management of acute myocardial infarction in patients presenting with ST-segment elevation: The Task Force for the management of acute myocardial infarction in patients presenting with ST-segment elevation of the European Society of Cardiology (ESC). Eur Heart J. 2018;39(2):119-177.

9. Bernat I, Aminian A, Pancholy S, Mamas M, Gaudino M, Nolan J, Gilchrist IC, Saito S, Hahalis GN, Ziakas A, Louvard Y, Montalescot G, Sgueglia GA, van Leeuwen MAH, Babunashvili AM, Valgimigli M, Rao SV, Bertrand OF. Best Practices for the Prevention of Radial Artery Occlusion After Transradial Diagnostic Angiography and Intervention: An International Consensus Paper. JACC Cardiovascular interventions.2019;12(22):2235-2246.

\section{Figures}

Figure 1. Electrocardiogram revealed premature ventricular contractions from outflow tract origin.

Figure 2. CT angiography of the whole aorta indicated aortic atherosclerosis, iliac arteries arteriosclerosis, multiple penetrating ulcers and aneurysm in aortic arch, infrarenal abdominal aortic thrombosis and occlusion.

\section{Figure 3.}

(A) Electroanatomic activation map (Carto 3, Biosense Webster, Diamond Bar, CA) of the left ventricle (colored) and anatomic map of the aortic root (gray). The zone of the earliest activation (orange) during premature ventricular contraction was identified close to the aortomitral continuity. Ablation was performed in this area (red dots) and abolished the PVC.

(B) Fluoroscopic images exhibiting the pacing sites in the AMC and the successful ablation site. AP = anteposition, $\mathrm{LAO}=$ left anterior oblique projection; $\mathrm{RAO}=$ right anterior oblique projection; $\mathrm{ABL}=$ ablation catheter.

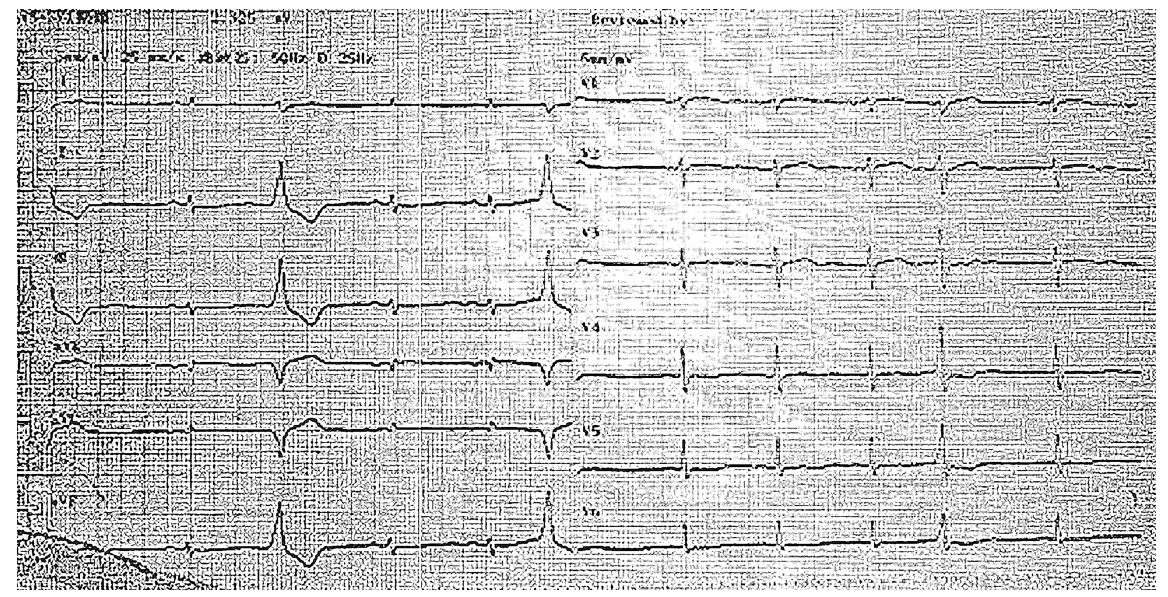



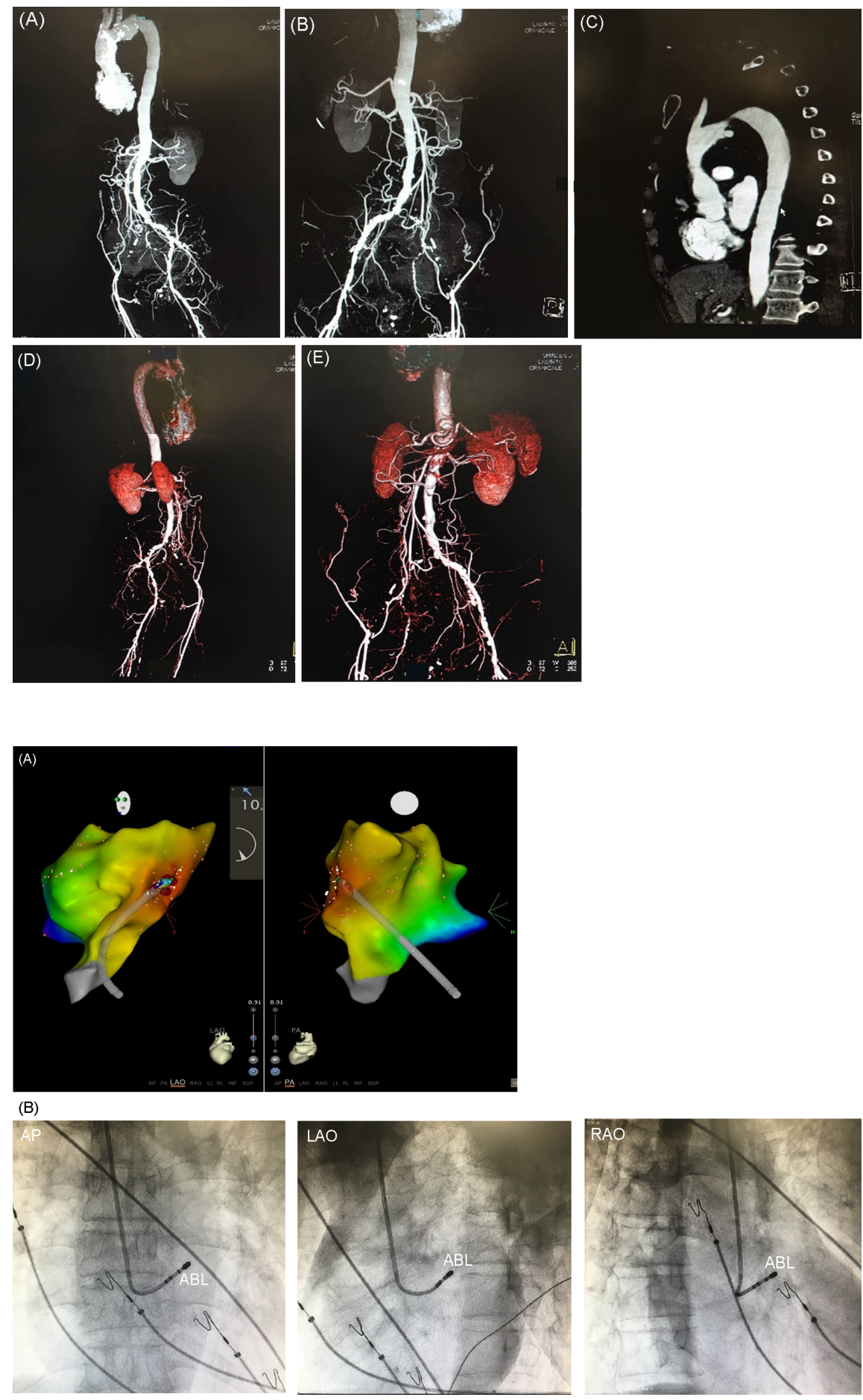